\title{
Validity and Reliability of the Short Form- 36 Items Questionnaire as a Measure of Quality of Life in Elderly Iranian Population
}

\author{
Seyed-Reza Eshaghi, Mohammad Arash Ramezani, Armindokht Shahsanaee and Arash Pooya \\ Department of Community Medicine, Isfahan Medical Sciences University, Iran
}

\begin{abstract}
The utility of The SF-36 questionnaire for evaluation of health related quality of life was not clear in elderly people. The Cross-Sectional study was designed and Iranian version of The SF-36 was administered to random sample of 100 old subjects over 60 years old. Finding showed good internal consistency over 0.7 for all subscales of questionnaire. Convergent validity was obtained for all subscales with comparison for General Health Questionnaire-28 (GHQ-28) but was not strongly at 2 subscales Role emotional and Role physical. Discriminant validity was addressed for gender but for age groups role emotional, mental health and general health subscales were not different significantly. A principal component analysis was leaded one factor structure. Evidence for reliability of the questionnaire was good. But validity appeared moderate satisfactory. However this questionnaire seems the only measure for assessment of health related quality at life among elderly population.
\end{abstract}

Key words: Validity, reliability, elderly, SF-36, quality of life, Iran

\section{INTRODUCTION}

It is now widely acknowledged that the medical outcome can not be described fully by measurement of clinical outcome and clinical indicators alone. Not only many factors such as pain, apprehension, financial situation have influence on health status but also subjective well-being effects on individuals health.

This approach conducted health related quality of life (HRQOL). Demand for subjective measured of HRQOL is increasing world wide. This in due to several factors, including The rising burden of chronic disease, the desire to measure the impact of health interventions beyond the absence of disease, the requirements at international organizations to estimate the impact of a wide variety of interventions to aid resource allocation and an increasingly global dissemination of knowledge through academic journals and international societies ${ }^{[1]}$.

Measures at HRQOL are commonly used in determining the affects at medical and communitybased health intervention comparing the health of different populations and assessing health needs.

It is considerable that old people proportions are increasing and there is a need to adders HRQOL in elderly people. The short from 36-item (SF-36) is a good standard instrument for evaluating at HRQOL ${ }^{[2-5]}$. It is a reliable and valid measure in multiple populations ${ }^{[6-12]}$. It has been tested for older adults in many surveys too ${ }^{[13-16]}$. We decided to stabilize whether the SF-36 is suitable for geriatrics and provide population scores for a representative sample of community-dwelling adults aged over 60 years in this study.

\section{MATERIALS AND METHODS}

At the community-based household survey in the catchments area of Shahinshahr; One of the city in Isfahan province of Iran, We selected 100 sample of people over 60 years from nearly 1600 population over 60 years old. Approximately, all the participants in the study were interviewed at home visit using three questionnaires to collect the following data:

1. Socio-demographic data including, gender, age, marital status, educational level, occupation, housing condition, financial states.

2. The quality of life that was used from Iranian version of the SF-36 questionnaire. This questionnaire had been translated to Persian and validated for Iranian population by Montazeri and coworkers- $2005^{[17]}$. We used this questionnaire with permission from them.

3. Perceived health status that was obtained from Iranian version of General Health Questionnaire-28 (GHQ-28) which, has been apply for health assessment for Iranian population and applied by Noorbala and coworkers ${ }^{[18]}$.

Data were analyzed by Spss-11.5 software. The SF-36 measures eight aspects at health status that were calculated for all subjects.

Reliability: Informed by the factor analysis as well as the theoretical concept behind the SF-36, we derived estimated internal reliability for each of the clusters of variables identified in the factor matrix. Internal reliability was estimated using Cronbach's alpha coefficient ${ }^{[19]}$.

Corresponding Author: Seyed-Reza Eshaghi, MD, MPH, Ass. Prof. of Community Medicine. Department of Community Medicine, Hezarjarib Street, Medical School, Isfahan Medical Sciences University, Isfahan, Iran, Tel: +983117922546, 
Validity: This was assessed by addressing convergent construct validity and Discriminant validity. Convergent construct validity was evaluated by comparing SF-36 subscales with GHQ subscales. Discriminant constructs validity was assessed by known group comparison to test how well the questionnaire discriminates between subgroups of the study sample that differed in gender and age. It was expected that women and older old people would home lower score than men and younger old people in all measures. In addition content validity was assessed using the correlation of each item with its hypothesized scale. Pearson correlation coefficient of 0.4 or above was considered satisfactory ${ }^{[17]}$. Further more, factor analysis of SF-36 questionnaire was performed by principal component analysis using varimax method ${ }^{[19]}$. P value < 0.05 was considered significant at every process of analysis.

\section{RESULTS AND DISCUSSION}

All 100 elderly individual had been approached that $88 \%$ was male. The mean age of the respondents was $67.2 \pm 6$ (mean $\pm \mathrm{SD}$ ). All at them was married. Item completion was complete.

Validity: For convergent construct validity, the correlation of eight subscales of SF-36 and the four subscales of GHQ-28 were shown in Table 2.

Discriminate construct validity was tested by difference between genders and age groups. All subscales of SF-36 questionnaire were significantly higher at male elderly respondents (Table 3 ).

Differences between young elderly (60-74 years) and old elderly people (75-90 years) among subscales score were significantly except at role emotional, mental health and general health (Table 4).

The principal component analysis with varimax rotation was performed one factor structure was loaded that jointly accounted $72.2 \%$ at the variance.

Reliability: Base on the above result, Cronbach's $\alpha$ statistics were estimated for the eight subscales of the SF-36. All subscales have internal reliability base on threshold of $\alpha=0.7$. The reliability coefficients were determined at Table 5.

Table 1: Pearson correlation coefficients between physical and mental health subscales at SF-36 and total mean score at GHQ-28

\begin{tabular}{lll}
\hline & Mean GHQ-28 & \\
\hline Physical Health SF-36 & Coefficient & 0.83 \\
& P Value & P $<0 / 0001$ \\
Mental Health SF-36 & Coefficient & 0.85 \\
& P Value & $\mathrm{P}<0.0001$ \\
\hline
\end{tabular}

Measurement of quality of life in the elderly needs standard outcome. The specific questionnaires for measurement of health-related quality of life in elderly are rare. Thus for assessment, generic questionnaires were approved. In the western world, different mode of outcome study short form like SF-36 and SF-20 were validated to elderly people ${ }^{[16,20]}$. The previous study had been determined that SF-36 was valid and reliable for Iranian people. Totally, SF-36 physical and mental health subscales ware high correlation with GHQ-28 scores (over 80\%).

Correlations between subscales were good except in the role physical and role emotional. One finding that has negotiation in our study is concern to analysis of factor structure. Principal competent analysis showed that only one factor structure was loaded from SF-36 questionnaire for geriatrics. This varied from other study. Because of in the other study at least 2 factors were loaded $^{[17]}$.

Known group comparison was done to test the scale validity one hypothesis was that women would have poorer health status than men which our analysis showed this. The other hypothesis was younger olds would have better health status than older people. Our finding determined that these differences were found the subscales exception in the Role emotional, Mental health, and general health. In these subscales there was no difference between younger old (66-74yreas) and older people (75-90).

All subscales exceeded the 0.7 level recommended for group competition. The SF-36 obtained very good internal consistency for elderly people.

Table 2: Correlation between eight SF-36 subscales and four GHQ-28 subscales

\begin{tabular}{|c|c|c|c|c|}
\hline \multirow[b]{2}{*}{ SF-36 } & \multicolumn{4}{|l|}{ GHQ-28 } \\
\hline & Somatic subscales & Anxiety subscale & Social function Subscale & Depression subscale \\
\hline Physical function & $\mathrm{r}=0.71$ & $\mathrm{r}=0.62$ & $\mathrm{r}=0.76$ & $\mathrm{r}=0.42$ \\
\hline Role limitation of physical function & $\mathrm{r}=0.6$ & $\mathrm{r}=0.48$ & $r=0.65$ & $\mathrm{r}=0.4$ \\
\hline Role limitation of emotional function & $\mathrm{r}=0.46$ & $\mathrm{r}=0.41$ & $r=0.56$ & $\mathrm{r}=0.48$ \\
\hline Vitality & $\mathrm{r}=0.83$ & $\mathrm{r}=0.75$ & $\mathrm{r}=0.81$ & $\mathrm{r}=0.57$ \\
\hline Emotional function & $\mathrm{r}=0.74$ & $\mathrm{r}=0.76$ & $\mathrm{r}=0.7$ & $\mathrm{r}=0.69$ \\
\hline Social function & $\mathrm{r}=0.81$ & $\mathrm{r}=0.68$ & $\mathrm{r}=0.79$ & $\mathrm{r}=0.65$ \\
\hline Pain & $\mathrm{r}=0.82$ & $\mathrm{r}=0.69$ & $\mathrm{r}=0.76$ & $\mathrm{r}=0.6$ \\
\hline General health perception & $\mathrm{r}=0.84$ & $\mathrm{r}=0.75$ & $\mathrm{r}=0.77$ & $\mathrm{r}=0.62$ \\
\hline
\end{tabular}

Significance level was $\mathrm{p}<0.0001$ for all coefficients 
Table 3: Comparison of the SF-36 scores for elderly population by gender

\begin{tabular}{|c|c|c|c|}
\hline \multirow[b]{2}{*}{ Subscales } & \multicolumn{3}{|l|}{ Sex } \\
\hline & Male mean (SD) & Female mean (SD) & $\mathrm{P}$ value \\
\hline Physical function & $66.6(25)$ & $55.4(22)$ & 0.031 \\
\hline Role limitation of physical function & $62.1(46.9)$ & $34.5(47.7)$ & 0.007 \\
\hline Role limitation of emotional function & $77.2(39.7)$ & $54(49)$ & 0.012 \\
\hline Vitality & $48(20.3)$ & $32.5(18.5)$ & $<0.0001$ \\
\hline Emotional function & $67.8(14)$ & $59.2(16)$ & 0.006 \\
\hline Social function & $81.8(23.6)$ & $68.4(27.9)$ & 0.012 \\
\hline Pain & $81.8(22.5)$ & $69.5(28.4)$ & 0.021 \\
\hline General health perception & $57.1(20.1)$ & $44.8(21)$ & 0.005 \\
\hline \multicolumn{4}{|l|}{ t test } \\
\hline \multicolumn{4}{|c|}{$\begin{array}{c}\text { Comparison at the SF-36 scores for elderly population by age group } \\
\text { Age group }\end{array}$} \\
\hline Subscales & 60-74 mean (SD) & 75-90 mean (SD) & $\mathrm{P}$ value \\
\hline Physical function & $66.3(22.7)$ & $34.5(20.5)$ & $<0.0001$ \\
\hline Role limitation of physical function & $55.9(49)$ & $27.3(39.5)$ & 0.045 \\
\hline Role limitation of emotional function & $70.7(44)$ & $57.6(47.3)$ & 0.354 \\
\hline Vitality & $44.6(21)$ & $27.3(13.8)$ & 0.009 \\
\hline Emotional function & $65.4(15.7)$ & $60.7(9.4)$ & 0.338 \\
\hline Social function & $79.5(15.7)$ & $60.7(6.4)$ & 0.012 \\
\hline Pain & $80.2(23.8)$ & $56.6(27.7)$ & 0.003 \\
\hline General health perception & $54.2(21.2)$ & $42.3(18.1)$ & 0.076 \\
\hline
\end{tabular}

t test

Table 5: Estimates of internal reliability the SF-36 questionnaire

\begin{tabular}{lll}
\multicolumn{2}{c}{ subscales } & \\
\hline Subscales & Cronbach's & $95 \%$ CI \\
\hline Physical function & $93.3 \%$ & $61.2-95.1$ \\
Role physical & $98 \%$ & $97.3-98.6$ \\
Role emotional & $95.7 \%$ & $94-97$ \\
Vitality & $91.3 \%$ & $88.2-93.8$ \\
Mental health & $77.3 \%$ & $69.5-83.7$ \\
Social function & $46.5 \%$ & $94.8-97.6$ \\
Bodily pain & $90 \%$ & $86-93.7$ \\
General health perception & $89 \%$ & $85-92$ \\
\hline
\end{tabular}

Data collection of this study was face to face interview. They had not any missing data and all sample completed the questionnaire. And we did not need missing data analysis.

In conclusion, Iranian version of the SF-36 is appraised for assessment health related quality of life for Iranian people ${ }^{[17]}$. But it considered that usage of this questionnaire for elderly in visa versa.

Reliability of this form in very good for all subscales but its validity for elderly seems moderately. Some subscales like role physical and role emotional didn't addressed strong and appropriate convergent validity.

Factor analysis showed at least two components for SF-36 subscales ${ }^{[17]}$. But our study showed only one loaded factor.

The present study does not provided evidence on test retest reliability or on responsiveness. Furthermore the sample size of our study was very low; further research project need to evaluate the appropriateness of SF-36 for geriatric.

To evaluate HRQOL in elderly population, it is recommended specific tool and we will try to make this questionnaire.

\section{REFERENCES}

1. Bowden, A. and J.A. Fox-Rushby, 2003. A systematic and critical review of the process of translation and adaptation of generic health-related quality of life measures in Africa, Asia, Eastern Europe, the Middle East, South America. Soc. Sci. Med., 57: 1289-1306.

2. Ware, J.E. Jr and C.D. Sherbourne, 1992. The MOS 36-item Short-Form Health Survey (SF-36): I. Conceptual framework and item selection. Med. Care, 30: 473-83.

3. McHorney, C.A., J.E. Jr. Ware and A.E. Raczek, 1993. The MOS 36-Item Short Form Health Survey (SF-36): II. Psychometric and clinical tests of validity in measuring physical and mental health constructs. Med. Care, 31: 247-63.

4. McHorney, C.A., J.E. Jr. Ware, J.F.R. Lu and C.D. Sherbourne, 1994. The MOS 36-Item Short Form Health Survey (SF-36): III. Tests of data quality, scaling assumptions, and reliability across diverse patient groups. Med. Care, 32: 40-66.

5. Ware, J.E. Jr, M. Kosinski, M.S. Bayliss, C.A. McHorney, W.H. Rogers and A. Raczek, 1995. Comparison of methods for the scoring and statistical analysis of SF-36 health profile and summary measures: Summary of results from the Medical Outcomes Study. Med. Care, 33: AS26479.

6. Wagner, A.K., K. Wyss, B. Gandek, P.M. Kilima and D. Whiting, 1999. A Kiswahili version of the SF-36 health survey for use in Tanzania: Translation and test of scaling assumptions. Qual. Life. Res., 8: 101-110. 
7. Taft, C., J. Karlsson and M. Sullivan, 2004. Performance of the Swedish SF-36 version 2. Qual. Life. Res., 13: 251-256.

8. Fukuhara, S.S. Bito, J. Green, A. Hsiao and K. Kurokawa, 1998. Translation, adaptation and validation of the SF-36 health survey for use in Japan. J. Clin. Epidemiol., 51:1037-1044.

9. Fuh, J.L., S.J. Wang and S.R. Lu et al., 2000. Psychometric evaluation of a Chinese version of SF-36 health survey amongst middle age women from a rural community. Qual. Life. Res., 9: 675683.

10. Li, L., H.M. Wang and Y. Shen, 2003. Chinese SF36 health survey. Translation, cultural adaptation, validation and normalization. J. Epidemiol. Community Health, 57: 259-263.

11. Sabbah, I., N. Drouby, S. Sabbah, N. Retel-Rude and M. Mercier, 2003. Quality of life in rural and urban populations in Lebanon using SF-36 health survey. Health Qual. Life. Outcome, 1: 30-37.

12. Tseng, H., J.R. Lu and B. Gandek, 2003. Cultural issue in using the SF-36 health survey in Asia; result from Taiwan. Health Qual. Life. Outcome, 1: 72-84.

13. Hayes, V., J. Morris, C. Wolfe and M. Morgan, 1995. The SF-36 health survey questionnaire: Is it suitable for use with older adults? Age Aging, 24: 120-125.
14. Brazier, J.E., S.J. Walter, J.P. Nicholl and B. Kohler, 1996. Using the SF-36 and EUROQOL on an elderly population. Qual. Life. Res., 5: 195-204.

15. Lyons, R.A., H.M. Perry and B.N.C. Littlepage, 1994. Evidence for the validity of the short form 36 questionnaire (SF-36) in an elderly population. Age Aging, 23: 182-4.

16. Walters, S.J., J.F. Munro and J.E. Brazier, 2001. Using the SF-36 with older adults: a cross-sectional community-based survey. Age Ageing, 30: 337-43 .

17. Montazeri, A., A. Goshtasebi, M. Vahdaninia and B. Grandek, 2005. The short form health survey (SF-36): Translation and validation study of Iranian version. Quali. Life. Res., 14: 875-82.

18. Noorbala, A.A., Bagheri Yazdi S.A., M.T. Yasami and K. Mohammad, 2004. Mental health survey of the adult population in Iran. Br. J. Psychiatr., 184 :70-73.

19. Munro, B.H., 2001. Statistical Methods for Health Care Research. 4th Edn. Lippincott Co., Philadelphia, pp: 303-331.

20. Carver, D.J., C.A. Chapman, V.S. Thomas, K.J. Stadnyk and K. Rockwood, 1999. Validity and reliability of the Medical Outcomes Study Short Form-20 questionnaire as a measure of quality of life in elderly people living at home. Age Ageing, 28: 69-74. 